\title{
Impacts of Pond Change on the Regional Sustainability of Water Resources in Taoyuan, Taiwan
}

\author{
Yuei-An Liou, Tai-Sheng Wang, and Hai-Po Chan \\ Center for Space and Remote Sensing Research (CSRSR), National Central University, Chung-Li 32001, Taiwan \\ Correspondence should be addressed to Yuei-An Liou; yueian@csrsr.ncu.edu.tw
}

Received 27 October 2013; Accepted 27 November 2013

Academic Editor: Chung-Ru Ho

Copyright (C) 2013 Yuei-An Liou et al. This is an open access article distributed under the Creative Commons Attribution License, which permits unrestricted use, distribution, and reproduction in any medium, provided the original work is properly cited.

\begin{abstract}
Taoyuan tableland faces the increasing water demand associated with the expansion of industrialization and urbanization. The county currently relies on the Shihmen Reservoir as the single water supply system. It will be of great concern in the shortage of water resources. This study aims to explore the impact of changes in farm ponds on the regional agricultural environment in Taoyuan County with multiyear $(1993,2003$, and 2010) SPOT satellite imagery. Results show that farm ponds have decreased by 10.55 million $\mathrm{m}^{2}$ from 1993 to 2010 , and the existing farm ponds were 18.80 million $\mathrm{m}^{2}$ in 2010, equivalent to the irrigation water of $21.10 \sim 31.65$ million $\mathrm{m}^{3}$ (tons) and 37.61 56.41 million $\mathrm{m}^{3}$ (tons), respectively. The existing farm ponds are able to provide the water supply for 1.88 2.82 thousand hectares of agricultural land, accounting for $6.70 \% \sim 10.50 \%$ of total agricultural area of Taoyuan County. Corresponding to the government's promotion policy (2012) on activating fallow land, if we redeploy the existing farm ponds for activating fallow fields, it will lessen the water supply burden of Shimen Reservoir. Thus, farm ponds remain the significant water facilities. For the sustainable agriculture, farm ponds shall be classified and cherished as a public asset for the future development.
\end{abstract}

\section{Introduction}

In the past agricultural society, people were plagued with insufficient water supply for field irrigation in Taoyuan tableland. Farmers usually dig farm ponds for the irrigation purpose by taking the advantages of the impermeable characteristics of red and yellow soil. At the peak period, there were nearly eight thousand ponds in Taoyuan County, brought the reputation such as "one-thousand-pond town" and "onethousand-lake County" [1]. However, since the 1920s, after the constructing of Shimen Reservoir, Taoyuan Canal and Shimen Canal, and other irrigation facilities, the ponds have gradually vanished. Coupled with the rapid expansion of industrialization and urbanization progress, the landscape development has been changed, which also brought the indirect impacts to the ponds. According to the statistics in 2008 , the number of ponds was about 3,345, but only around 2,800 left by the year of 2009 [2].

Since the year of 1983, Taiwan government implemented the six-year plan on rice production and paddy field transfer to address the financial issue of poor rice sales. However, it is not until 1995 the rice supply and demand has reached balance [3]. The land fallowing policy caused the agricultural land fallow area rapid increase, thus resulted in the rice field area decline of $40.78 \%$ from 1983 to 2006 [4]. According to the statistics 2011, the fallow land area in Taoyuan County summed up to 26.86 thousand hectares [5], demonstrating the main reason of ponds disappearance.

Taiwan initiated the land fallow policy for nearly 28 years since the accession to the World Trade Organization. As much as 200 thousand hectares agricultural land has fallow in the whole island, and these fallow lands not only breed weeds, pests, and rodents but also spend the government annual budget for maintenance. In recent years, global climate change has caused the volatile food supply internationally. The government plans to promote the activation of fallow land in the hope to boost the food self-sufficiency rate [6].

The existing farm ponds in Taoyuan County can be redeployed as the irrigation facilities and improve irrigation water recycling rate for the regional agriculture development. Therefore, this study combined multiyear $(1993,2003$, and 2010) SPOT satellite imagery and statistical analysis to investigate the land-use and land-cover (LULC) changes impact on the regional agriculture environment. Analysis 
assessments on the usage possibility of existing ponds for regional irrigation and farmland water conservancy facilities are also provided.

\section{Remote Sensing and Water Reuse}

2.1. Remote Sensing and Land Change. Remote sensing technology has been developed since the 1960s. With the advance of modern physics, spatial technology, electrical technology, computer technology, information technology, environment technology, and so on, it becomes an up-to-date and feasible integral detection method [7-9]. Satellite remote sensing is a reliable full-length, real-time, and periodical data acquisition technology. The application of these techniques on the largescale LULC change provides not only the basic spatial information, but also the assistance for the better decision making on the environmental resources control aspect [10]. Remote sensing has been widely used in agriculture, forestry, geology, geography, geomorphology, oceanography, hydrology, meteorology, LULC change, landscape change monitoring, earth resource exploration, military reconnaissance, and other various areas [7].

Remote sensing technology provides key tools for the earth and environment observations. Satellite remote sensed data for land cover, land use, and its changes play a key role for many diverse applications. Natural resource management, planning, and monitoring programs rely on accurate data of the land cover in the target region. In addition, compared to other monitoring methods, the extensive analysis of remotely sensed data has proven to be more cost effective for large regions.

LULC change can be regarded as a social process to meet human's needs, and thus its development is strongly dependent on environmental and social factors. Therefore, understanding and effectively controlling the process of LULC change are the hot issue for the regional sustainable development such as environmental protection and natural resources exploitation. LULC data in different periods can be used to investigate the LULC change in urban areas by the statistical analysis and thus display the LULC change in each period [11].

2.2. Water Reuse. For the agricultural irrigation needs in early days, farm ponds were excavated as the main water facilities because of terrain and environment features in Taoyuan tableland. However, since the construction of Shimen Reservoir, Taoyuan Canal, and Shimen Canal, the original functions of farm ponds have been replaced. The proposed fallow grants policy in the past decades also likely caused farm ponds to vanish gradually (decreased from 8,000 at the peak period to 2,800 in the year of 2010).

Water reuse offers a climate independent water source that is dependable, locally controlled, and generally beneficial to the environment. Water reuse also allows communities to become less dependent on groundwater and surface water sources and can decrease the diversion of water from sensitive ecosystems.
Dyer [12] had raised awareness on water crisis issues, pointing out that although the earth's arable land area increased by only $10 \%$ in the past, irrigation water has increased threefold, indicating the increasing water demand in the world. More water and energy are required to meet the food production, as well as industrial, services, and other livelihood and development needs. According to the report from United Nations in 2013, due to the global population growth and climate change, water use around the globe becomes increasingly competitive. One-third of the population in the world is under the middle and high levels of water scarcity. By 2030, nearly half the world's population will face the issue of water shortages. Water demand is expected to increase by $40 \%$, coupled with the rise of emerging market economies, and water demand will grow geometrically. The future evolution trend of water use is more people worldwide with less water. It is estimated that, by $2050,45 \%$ of the world population and the country will be affected by the chronic shortage of water resources, indicating that the issue becomes increasingly serious.

Water conservation and recycling issues have raised a worldwide attention. The event such as the World Water Day on March 22, 2013, proposed a "Recycle a Bucket of Water a Day" slogan to advocate for the sustainable management of freshwater resources in the planet. Therefore, in addition to the wastewater recycling plan in Taoyuan County, the existing pond facilities can be redeployed as the small-size artificial reservoir to uplift the usage of water resources.

\section{Study Areas and Methods}

3.1. Study Area. Taoyuan County locates in the tableland, northwest of Taiwan, a total of 13 townships, including Xinwu Township, Guanyin Township, Dayuan Township, Luzhu Township, Gueishan Township, Taoyuan Township, Bade Township, Chungli Township, Yangmei Township, Pingzhen Township, Longtan Township, Daxi Township, and Fusing Township, as shown in Figure 1. Most lands in Taoyuan are barren soil because of its terrain features. This study focuses on LULC changes of the pond (water body) and farmland (vegetation) areas. In order to exclude the influence of water bodies such as rivers and reservoirs in this area, image processing technology was applied to trim the area along the boundaries of hills and rivers of Taoyuan County. The preprocessed study area image is shown in Figure 2.

3.2. Image Processing. The goal of image processing is to create an enhanced image that is more useful or to perform some of the interpretation and recognition tasks. We took various periods of SPOT satellite imagery, including the 1993 (SPOT2), 2003 (SPOT-5), and 2010 (SPOT-5), with the spatial resolution of $12.5 \mathrm{~m}, 10 \mathrm{~m}$, and $10 \mathrm{~m}$, respectively. However, as the radiation image, satellite images were distorted or deformed with geometric errors because of atmospheric scattering, sun angle difference, vehicles form, surface curvature of the flight trajectory parameters, other factors and etcetera. To correct the above errors and acquire the true data, we applied the following three steps: (i) image preprocessing; (ii) image classification, and (iii) image accuracy assessment. 


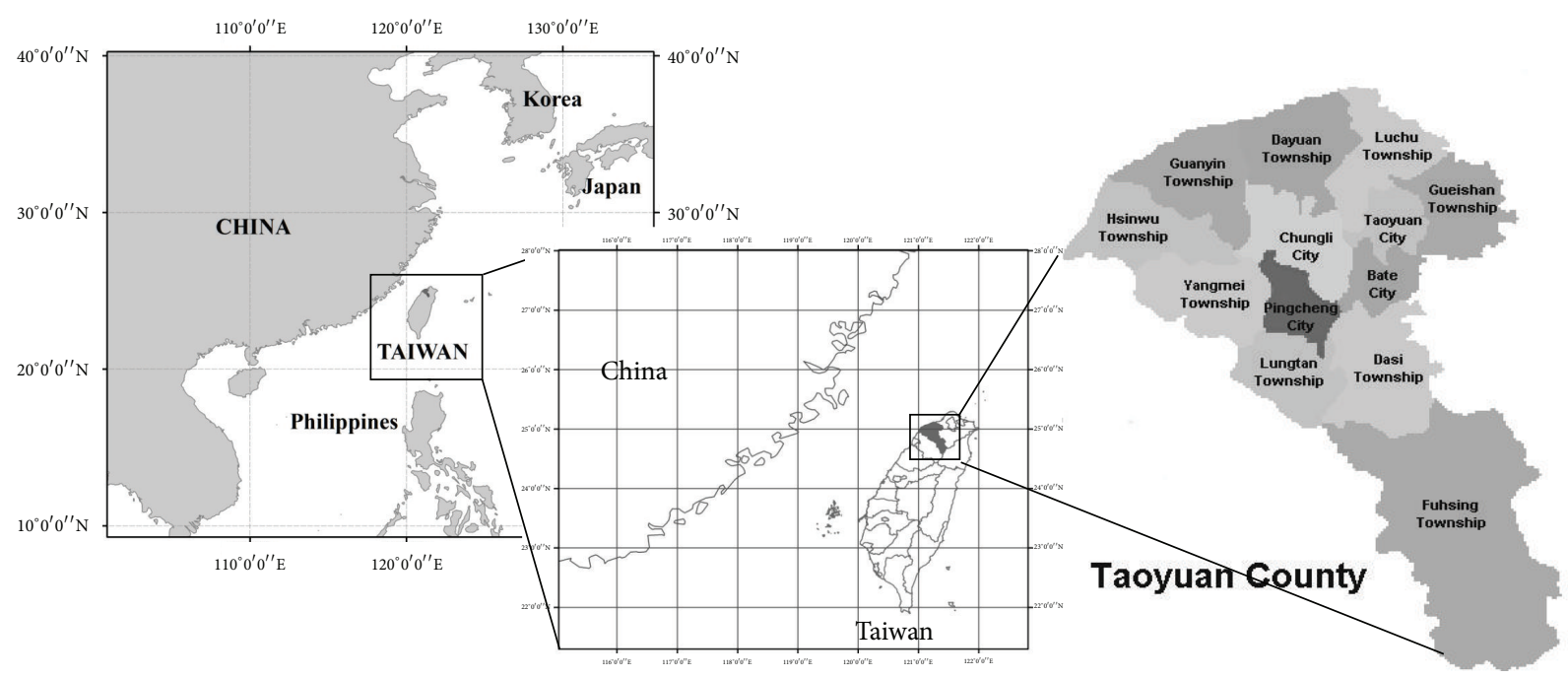

Figure 1: Geographic location of Taoyuan County, Taiwan.

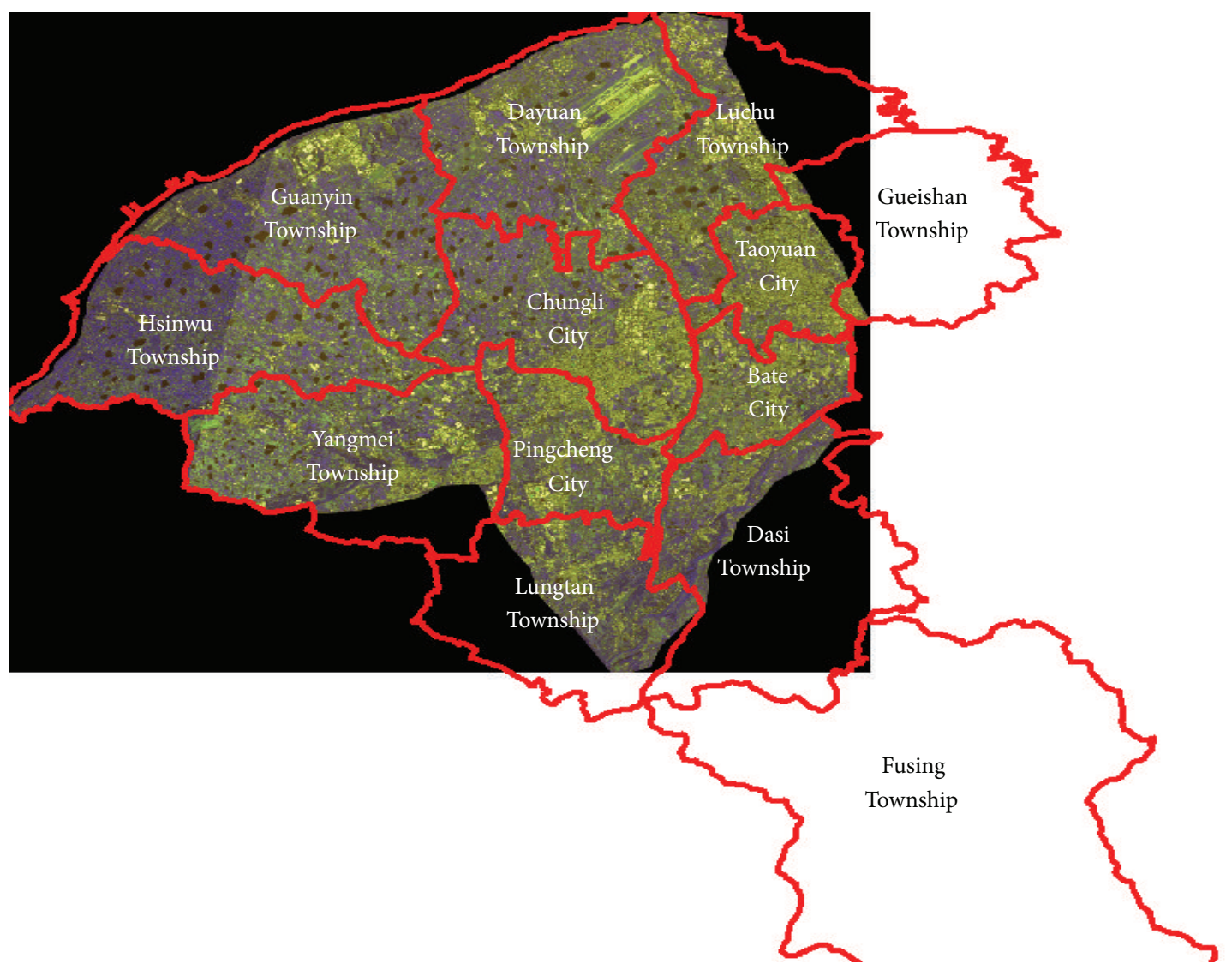

FIGURE 2: Preprocessed study area (excluding highlands (forest) and reservoir (water body)).

3.3. Image Classification. The basic principle of image classification lies in the fact that similar objects have similar spectral properties. The electromagnetic radiation reflected by objects of the same nature is similar overall and these objects will thus have similar spectral signatures. Since the spectral signatures of the objects observed by satellites are converted into different colors in digital images, objects of the same kind will appear in closely related colors. Besides, the colors in a digital image are merely a conventional transposition of numerical values; it is also possible to classify the pixels by their numerical values.

Satellite image classification methods are broadly divided into supervised and unsupervised classifications. Both use the similarity measure, but the former classifies images according 


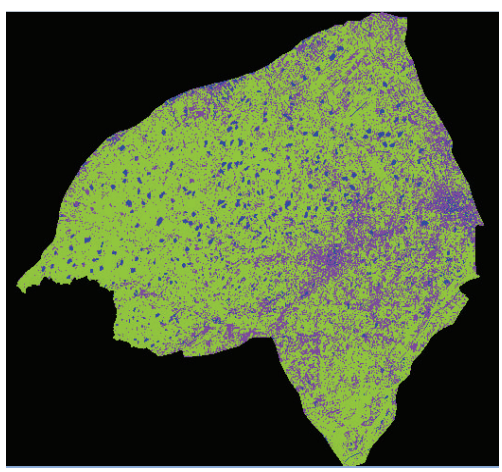

(a)

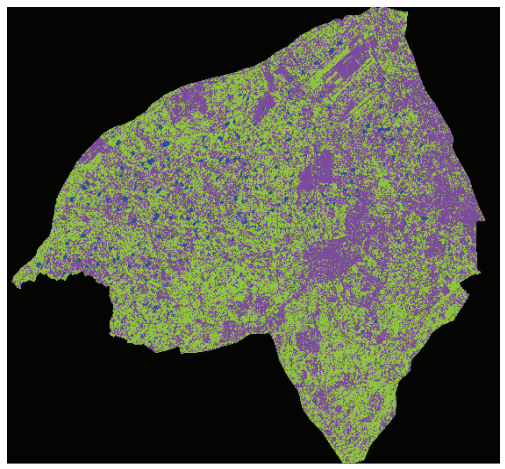

(b)

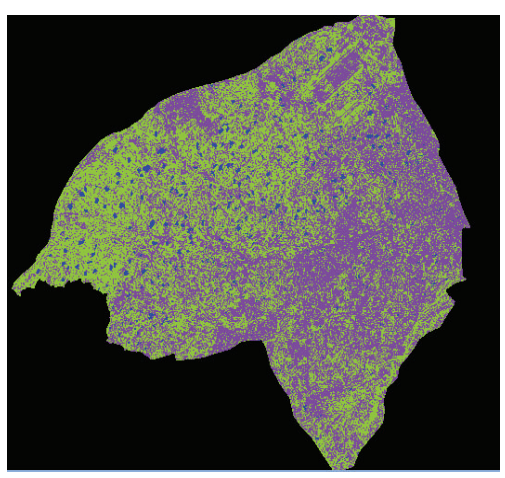

(c)

FIgURE 3: Color indexed LULC classification map from the SPOT series of satellites (blue: water body; green: vegetation; purple: nonvegetation). (a) 1993 SPOT-2; (b) 2003 SPOT-5; (c) 2010 SPOT-5.

TABLE 1: The accuracy assessment of images classification.

\begin{tabular}{lccc}
\hline Accuracy assessment & \multicolumn{3}{c}{ Year } \\
& 1993 & 2003 & 2010 \\
\hline Overall accuracy & $93.26 \%$ & $92.88 \%$ & $94.38 \%$ \\
Kappa index & 0.84 & 0.88 & 0.90 \\
\hline
\end{tabular}

to the similarity with a set of pregiven images ("references" or "templates"), and the latter classifies the images according to the innate grouping or clustering within the images.

In detail, each pixel on the image is classified according to the recorded surface spectral reflectivity (DN value). Using the specific statistical and analysis process, each pixel in the
TABLE 2: The statistics of LULC changes in 1993, 2003, and 2010.

\begin{tabular}{lccc}
\hline Feature type & $1993\left(\mathrm{~m}^{2}\right)$ & $2003\left(\mathrm{~m}^{2}\right)$ & $2010\left(\mathrm{~m}^{2}\right)$ \\
\hline Water body & $29,352,656$ & $18,945,800$ & $18,804,200$ \\
Vegetation & $444,161,250$ & $310,832,500$ & $281,818,300$ \\
Nonvegetation & $156,671,563$ & $300,244,100$ & $329,399,900$ \\
Total & $\mathbf{6 3 0 , 1 8 5 , 4 6 9}$ & $\mathbf{6 3 0 , 0 2 2 , 4 0 0}$ & $\mathbf{6 3 0 , 0 2 2 , 4 0 0}$ \\
\hline
\end{tabular}

image was thus given a specific value, which represents the particular category of land cover [13].

3.4. Accuracy Assessment. The accuracy of a classification is assessed by comparing the classification with reference data that is believed to accurately reflect the true land cover. Sources of reference data include among others ground truth data, higher resolution satellite images, and maps derived from aerial photo interpretation. Hence, the accuracy assessment reflects the difference between the classification and the reference data.

In this study, the accuracy of the image classification is estimated by the error matrix. Error matrix is used to compare the classified image and ground truth data for the accuracy assessment (the producer's accuracy and user's accuracy).

\section{Results and Discussion}

4.1. Image Analysis. By taking advantage of multiyear SPOT satellite imagery $(1993,2003$, and 2010), we have classified the data into three categories (Figure 3): (i) water body area (ponds), (ii) vegetation area (farmland), and (iii) nonvegetation area (buildings and bare land) in accordance with the unsupervised classification (Iterative Self-Organizing Data Analysis Techniques; ISODATA Classification).

To assess the accuracy of classification, we also randomly selected 267 points in the study area and artificially assigned the land cover category as ground truth data. The derived error matrix and Kappa index (Table 1) are greater than $90 \%$ and 0.8 and thus display that the image classification result is of high reliability.

4.2. Statistical Analysis. Land cover changes among 1993, 2003, and 2010 as shown in Table 2. Results show that nonvegetation area has increased $110 \%$ (172.73 million $\mathrm{m}^{2}$ ), the water body has reduced $35.94 \%$ (10.55 million $\mathrm{m}^{2}$ ), and the vegetation area has lost $36.55 \%$ (162.34 million $\mathrm{m}^{2}$ ) in Taoyuan County between the year of 1993 and 2010, individually. Furthermore, we find that $6.2 \%$ of nonvegetation (buildings and bare land) area came from the water body (ponds) area and $93.8 \%$ from the vegetation (farmland) area during the past 18 years.

4.3. Ponds Change. The water storage in farm ponds provides the water resources for farmland irrigation; the disappearance of farm ponds thus impacts the regional agriculture environment in Taoyuan County. If we ignore the influence of hydrological factors such as infiltration and runoff, the 
vanishing ponds water storage is $21.10-31.65$ million tons for the average depth of 2 3 meters of farm ponds [5]. Again, if we make assessment based on the requirement of 0.02 million tons of irrigation water for one hectare of farmland each time [14], the vanishing ponds water could supply for approximately 1.06 1.58 thousand hectare farmland. However, the total area of existing farm ponds was approximately 18.80 million $\mathrm{m}^{2}$ in 2010 , equivalent to the irrigation water of 37.61 56.41 million tons. This means that if we take advantage of the existing farm ponds for activating fallow fields, it will subsequently reduce the water supply burden of Shimen Reservoir. Therefore, the ponds remain the significant water facilities in this region.

4.4. Fallow Land Activation. In recent years, Taiwan government promotes policy of food self-sufficiency and at same time reduces fallow subsidies to activate the fallow land. Nevertheless, the prerequisite is to tackle the issue of increasing demand of water use. If the county government continues to rely on the Shihmen Reservoir as the unitary water supply system for civilians, industries, and farm irrigations, it will be a great concern for regional agricultural development in the water shortage. According to statistics in 2011, the existing fallow land is around 26.86 thousand hectares in Taoyuan County [5]. Once collaborating with the government activation policy on fallow land, the existing farm ponds are able to provide $6.7 \% \sim 10.5 \%$ water use for irrigation. Moreover, if the ponds can be deepened around one meter above the average depth, the maximum water storage of ponds will increase to approximately 75.22 million tons, which accounts for nearly half (48.94\%) of the irrigation water demand. This deployment obviously improves the regional water reuse rate. Hence, if the county government takes advantage of existing ponds to water fallow farmland, it will not only relieve the burden of the reservoir but also save the ponds from disappearance and thus help stabilize the Taoyuan regional agriculture development and uplift food self-sufficiency rate.

\section{Conclusions}

Satellite remote sensing is a reliable full-length, real-time, and periodical data acquisition technology. The application of these techniques on the large-scale LULC change not only provides the basic spatial information, but also the assistance for the better decision making on the environmental resources control aspect. Research results on the changes of LULC over the past 18 years (from 1993 to 2010) in Taoyuan show that the increasing rate of nonvegetation (buildings and bare land) area is $110 \%$, the decreasing rate of water body (ponds) area is $35.94 \%$, and the decreasing rate of vegetation area is $36.55 \%$, respectively. Also, image change detection analysis implies that the nonvegetation (buildings and bare land) areas are primarily converted from the vegetation (farmland) areas. Therefore, we are able to catch the whole picture of LULC changes in the study area and comprehend its potential impacts on the regional sustainable development and also to provide the proactive fact-grounded policy recommendations for the government agencies. The future work will be the focus of higher resolution satellite images applying to distinguish LULC change and the corresponding impact on the social, economic, and natural environment, such as the urban desertification issue. Such work is especially required because many issues concerning the expected environmental changes and societal impacts associated with the recently approved Tauyuan Aerotropolis Project in 2013 remain unknown. It is planned that the initial investment and the developed area of the Tauyuan Aerotropolis Project are 495 billion NTD ( 16.5 billion USD) and 6770 acres, respectively.

\section{Acknowledgments}

The authors are extremely grateful to the CSRSR (Center for Space and Remote Sensing Research, National Central University) satellite receiving station for providing the image from SPOT-2 and SPOT-5. This work was supported by the National Science Council (NSC) under the Grants NSC 1012221-E-008-019 and NSC 101-2111-M-008-018.

\section{References}

[1] H. T. Chen, "From ponds to irrigations: the evolution of the water resources in Taoyuan Plateau," Dong Hwa Journal of Humanities, no. 5, pp. 183-208, 2003.

[2] S. J. Chyi and H. J. Wu, "Taoyuan tableland Encyclopedia of Taiwan, 2009," http://taiwanpedia.culture.tw/web/index.

[3] Y. C. Teng, "Review and prospect of Taiwan's rice," in Research Report, Introduction to Kaohsiung District Agricultural Research and Extension Station, vol. 14, no. 3, pp. 1-23, 2003.

[4] R. G. Jiang, "Management and use of fallow paddy," in Introduction to Taitung District Agricultural Research and Extension Station, 2008.

[5] Spatial Planning of Agricultural Land, "The correction results of spatial planning of agricultural land resources in Taoyuan County in 2011".

[6] The Official Website of Council of Agriculture, http://eng.coa .gov.tw/.

[7] Y. A. Liou, S. K. Kar, and L. Y. Chang, "Use of high-resolution formosat-2 satellite images for post-earthquake disaster assessment: a study following the 12 may 2008 Wenchuan earthquake," International Journal of Remote Sensing, vol. 31, no. 13, pp. 33553368, 2010.

[8] Y. A. Liou, H. C. Sha, T. M. Chen et al., "Assessment of disaster losses in rice field and yield after tsunami induced by the 2011 Great East Japan earthquake," Journal of Marine Science and Technology, vol. 20, no. 6, pp. 618-623, 2012.

[9] T. Y. Chang, Y. A. Liou, C. Y. Lin, S. C. Liu, and Y. C. Wang, "Evaluation of surface heat fluxes in Chiayi Plain of Taiwan by remotely sensed data," International Journal of Remote Sensing, vol. 31, no. 14, pp. 3885-3898, 2010.

[10] T. S. Wang, Application of various-scale satellite images to inland water quality monitoring in Taiwan [Ph.D. thesis], Department of Civil Engineering and Engineering Informatics, 2010.

[11] T.-Y. Chou, F.-J. Chien, and T.-C. Lei, "Quantitative analysis study for land use changes detection of urban area," Journal of Taiwan Land Research, vol. 6, no. 1, pp. 105-130, 2003.

[12] G. Dyer, Climate Wars, Random House of Canada, 2010. 
[13] Z. H. Tan, "Investigation of the paddy heat sink effect and economic evaluation in Taiwan," Operation of Irrigation Associations, pp. 25-49, 2009.

[14] The Official Website of Taoyuan County Government, "the correction results of spatial planning of agricultural land resources in Taoyuan County in 2008," http://www.tycg.gov.tw/files/IMC/ aB0006996.pdf. 

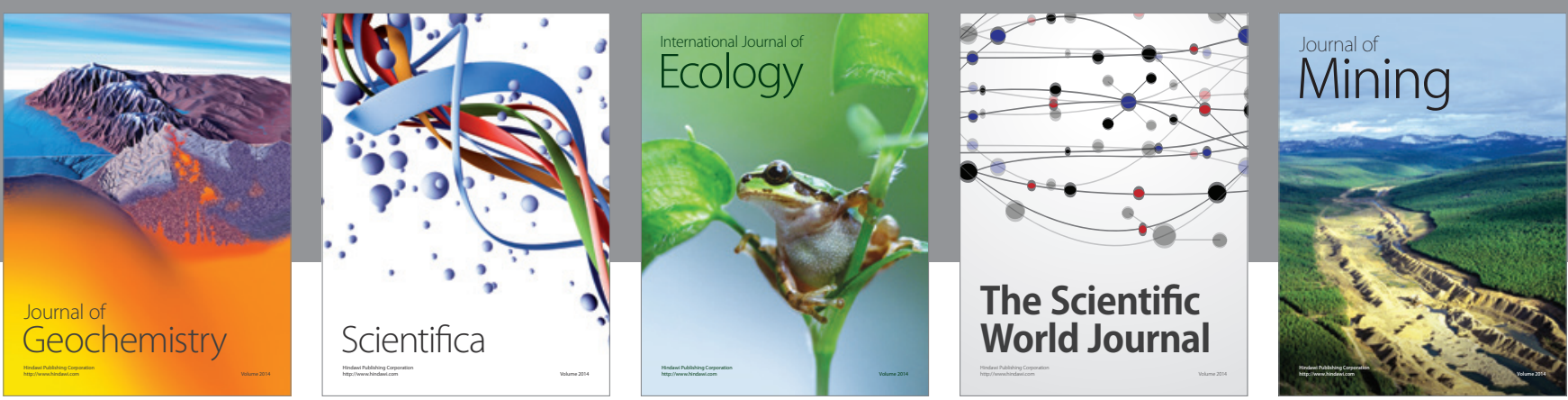

The Scientific World Journal
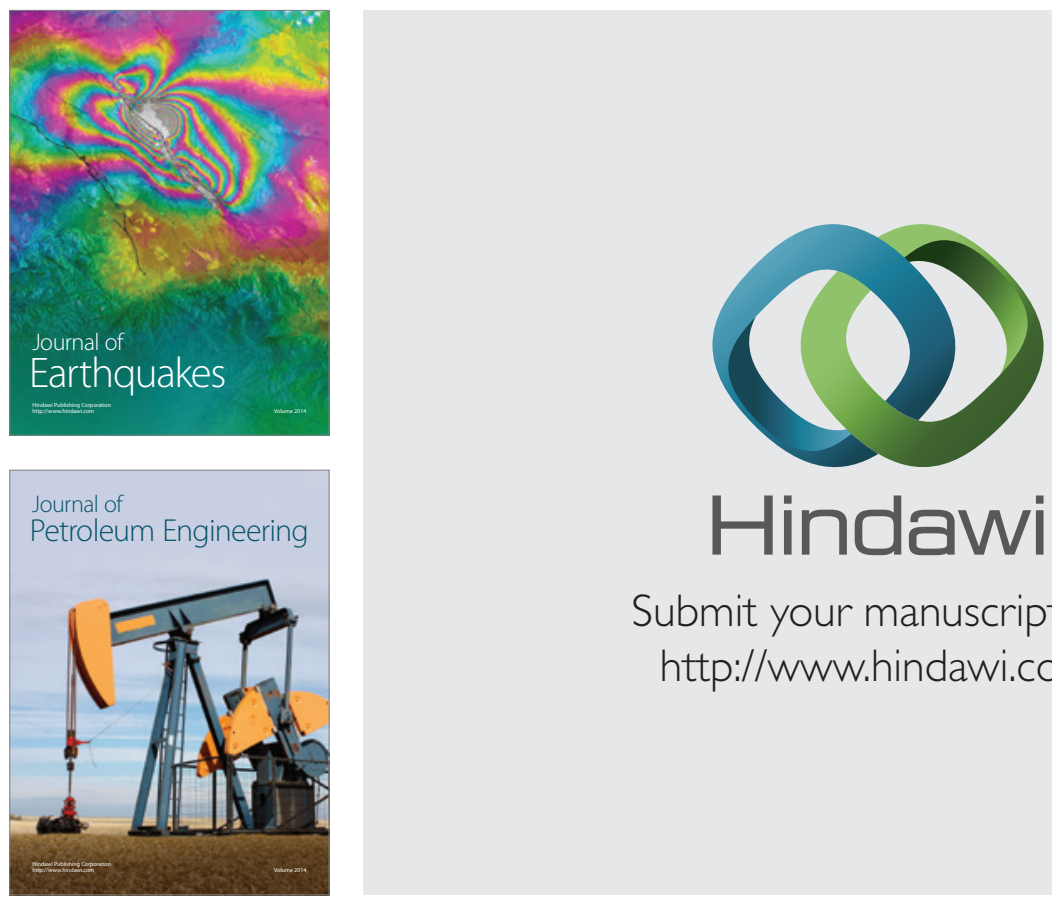

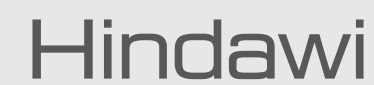

Submit your manuscripts at

http://www.hindawi.com
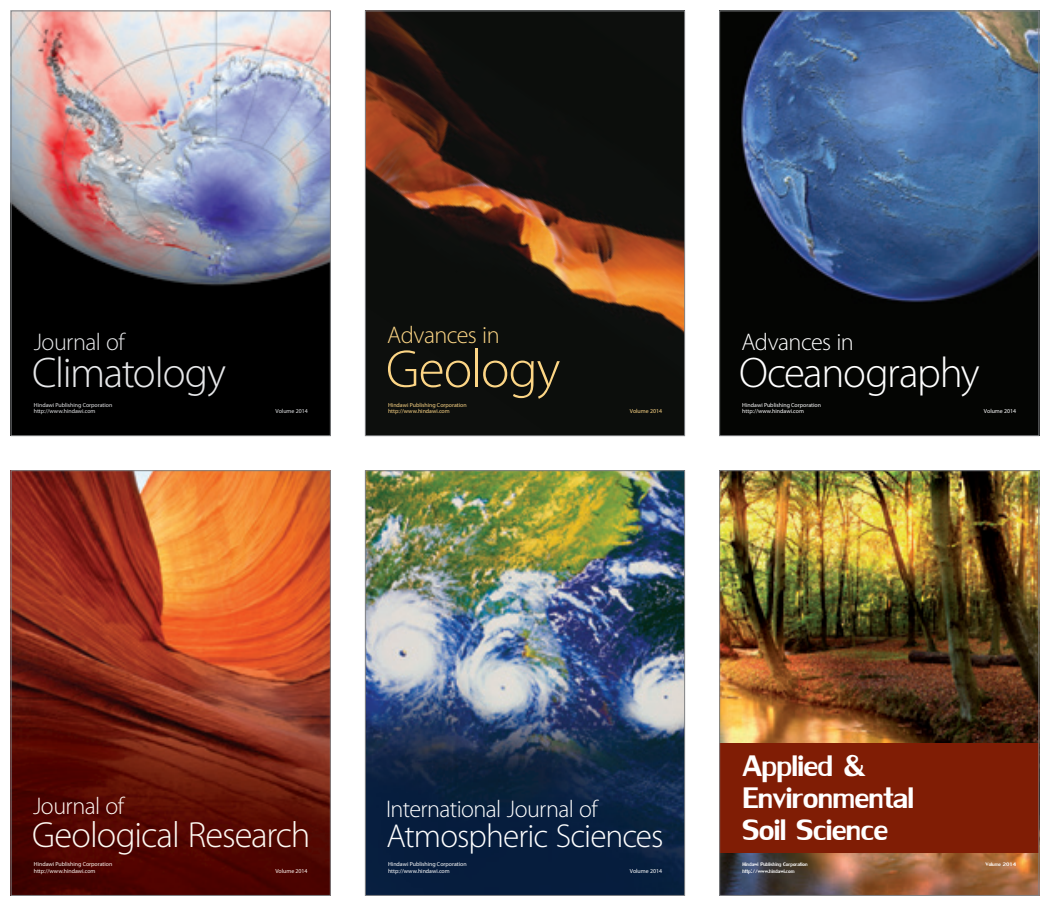
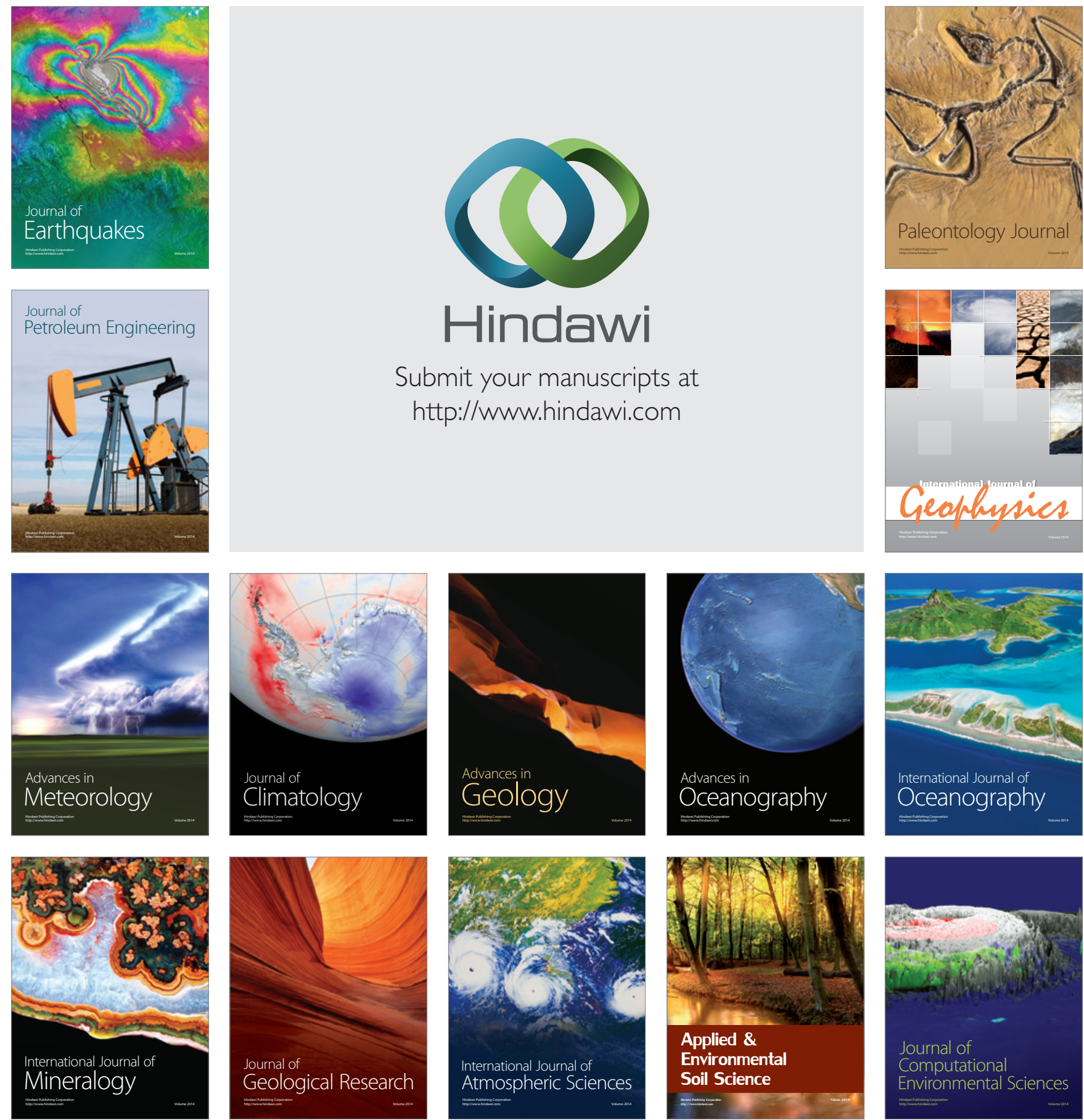